\title{
On the formation of nanocrystalline active
}

\section{zinc oxide from zinc hydroxide carbonate}

\author{
Amir Moezzi ${ }^{1,2}$, Michael Cortie $^{1 *}$, Annette Dowd $^{1}$ and Andrew McDonagh ${ }^{1}$
}

1. Institute for Nanoscale Technology, University of Technology Sydney, Sydney NSW

2007, Australia

2. Avocado Engineering Pty. Ltd., 6/5 Lusty Street Wolli Creek NSW Australia 2205

*Corresponding author: email michael.cortie@uts.edu.au

telephone: +61-422-771-021

\begin{abstract}
The decomposition of zinc hydroxide carbonate, $\mathrm{Zn}_{5}\left(\mathrm{CO}_{3}\right)_{2}(\mathrm{OH})_{6}$, into the high surface area form of $\mathrm{ZnO}$ known as 'active zinc oxide' is examined. In particular, the nucleation and evolution of the $\mathrm{ZnO}$ nanocrystals is of interest as the size of these particles controls the activity of the product. The decomposition process was studied using X-ray diffraction, thermogravimetric analysis, scanning electron microscopy, transmission electron microscopy and BET surface area measurements. At about $240{ }^{\circ} \mathrm{C}$ zinc hydroxide carbonate decomposes to porous zinc oxide in a single step. The product material has a specific surface area in the range of 47 to $65 \mathrm{~m}^{2} / \mathrm{g}$ and initially has a crystallite size that is of the order of $10 \mathrm{~nm}$. A further increase in temperature, however, causes the particles to coarsen to over $25 \mathrm{~nm}$ in diameter. In principle, the coarsening phenomenon may be interrupted to control the particle size.
\end{abstract}

Keywords Zinc oxide; Active zinc oxide, Activated zinc oxide, Layered basic zinc salts, Zinc hydroxide carbonate; Basic zinc carbonate; Hydrozincite; Phase transformation 


\section{Introduction}

Nanoparticles of 'active' or 'activated' zinc oxide are commercially important due to their relatively high specific surface area (30 to $70 \mathrm{~m}^{2} / \mathrm{g}$ ) and their chemically reactive nature. This form of zinc oxide is used in a variety of applications such as in rubber for inner tubes and latex gloves, and in desulfurization processes (Moezzi et al., 2012, Robinson, 1978, Nip, 2003) and is usually produced by calcining zinc hydroxide carbonate in the 200 to $400{ }^{\circ} \mathrm{C}$ range (Liandi, 1995, Moezzi et al., 2012, Robinson, 1978). The zinc hydroxide carbonate precursor (also known as hydrozincite or basic zinc carbonate) is generally considered to have the stoichiometry $\mathrm{Zn}_{5}\left(\mathrm{CO}_{3}\right)_{2}(\mathrm{OH})_{6}$, although some other compositions such as $\mathrm{Zn}_{3} \mathrm{CO}_{3}(\mathrm{OH})_{4}$ (Liu et al., 2004, Sawada et al., 1996) and $\mathrm{Zn}_{4} \mathrm{CO}_{3}(\mathrm{OH})_{6} \cdot \mathrm{H}_{2} \mathrm{O}$ ( $\mathrm{Li}$ et al., 2005) are possible too. 'Active' $\mathrm{ZnO}$ is a distinctly different product to the more crystalline 'French' or 'American' process zinc oxides, which are produced by high temperature $\left(>900{ }^{\circ} \mathrm{C}\right)$ pyrometallurgical processes. These latter products also have a much lower specific surface area $\left(<12 \mathrm{~m}^{2} / \mathrm{g}\right)$ and are produced in far greater quantities than active $\mathrm{ZnO}$ (Moezzi et al., 2012).

The mechanism and kinetics of the thermal decomposition of $\mathrm{Zn}_{5}\left(\mathrm{CO}_{3}\right)_{2}(\mathrm{OH})_{6}$ and similar zinc hydroxide carbonates have been investigated previously (Nobari and Halali, 2006, Li et al., 2005, Liu et al., 2004, Kanari et al., 2004, Sawada et al., 1996, Dollimore et al., 1980, Castellano and Matijevic, 1989). Although the decomposition is energetically favourable above about $160{ }^{\circ} \mathrm{C}$ (Moezzi et al., 2012), at that temperature the reaction takes hundreds of hours to complete (Kanari et al., 2004). The rate of decomposition only becomes significant above about $240{ }^{\circ} \mathrm{C}$ (Liu et al., 2004, Nobari and Halali, 2006). The activation energy for the reaction is of the order of $100 \mathrm{~kJ}$ per mole of $\mathrm{Zn}_{5}\left(\mathrm{CO}_{3}\right)_{2}(\mathrm{OH})_{6}$ (Nobari and Halali, 2006). The kinetics can be explained with a shrinking core model (Nobari and Halali, 2006) but there has been discussion in the literature on whether a one- or two-step model for the decomposition is required (Li et al., 2005, Kanari et al., 2004). Nevertheless, it is generally observed that de-carboxlation and de-hydroxlation occur simultaneously (Nobari and Halali, 2006, Li et al., 2005, Liu et al., 2004, Kanari et al., 2004), however these processes may be separate in the specific case of the calcination of $\mathrm{ZnCO}_{3} \cdot \mathrm{ZnO} \cdot 2 \mathrm{H}_{2} \mathrm{O}$ (Dollimore et al., 1980). The particle size of the $\mathrm{ZnO}$ produced is normally in the range 20 to $30 \mathrm{~nm}$ and some dependence of particle size and/or crystallinity on temperature was noted ( $\mathrm{Li}$ et al., 2005). This latter point is interesting as it implies that fine control of the structure of the $\mathrm{ZnO}$ produced may be obtained by careful control of the calcination temperature and time. However, despite its obvious practical implications, this aspect of the decomposition reaction seems not to have been hitherto investigated. Here we address this issue using data collected from in-situ synchrotron XRD, supported by SEM, TEM, BET and DTA/TGA. 


\section{Experimental}

General

AR grade sodium carbonate and zinc sulfate heptahydrate were purchased respectively from Chem-Supply Pty Ltd and Ajax Chemicals (both of Sydney, Australia) and used as-received. MilliQ water (18.2 $\left.\mathrm{M} \Omega \mathrm{cm}^{-1}\right)$ was used as solvent. Reactions were conducted under atmospheric conditions using a two-neck round bottom flask with a digitally-controlled magnetic heater/stirrer. A magnetic stirrer bar was used at a stirring rate of 820 rpm.

Synchrotron powder XRD studies were conducted at the Australian Synchrotron using $0.3 \mathrm{~mm}$ diameter $\mathrm{SiO}_{2}$

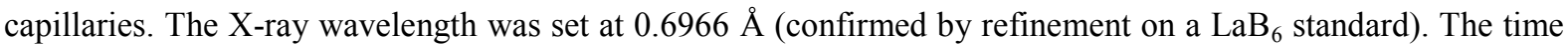
stamp corresponded to the beginning of each two-minute collection interval and the sample was ramped at 5 ${ }^{\circ} \mathrm{C} \cdot \mathrm{min}^{-1}$. Therefore the representative temperature for a data block undergoing heating ramp is $5{ }^{\circ} \mathrm{C}$ higher than the logged temperature. 3D and color-coded contour graphs were generated using MATLAB version 7 without subtracting the background. Intensity data were corrected by division of the intensity figure by the integrated ion chamber count figure multiplied by $10^{5}$ to form an arbitrary unit.

Parameters of the strong (200) peak of zinc hydroxide carbonate (ZHC) $(\sim 0.68 \mathrm{~nm}$ at room temperature) and the combined $(010) /(100)$ peaks of $\mathrm{ZnO}\left(0.281 \mathrm{~nm}\right.$ at $\left.230{ }^{\circ} \mathrm{C}\right)$ were extracted by fitting a pseudoVoight $(50 \%$ Lorentzian, 50\% Gaussian) model to data in an appropriate range of $2 \theta$ values, using a cubic polynomial as background. Fitting was achieved using Fityk (Wojdyr, 2010), called in turn by a script generated automatically by a Pascal program which stepped through the individual diffraction data files. An estimate of the size of crystalline $\mathrm{ZnO}$ domains $\left(\mathrm{D}_{\mathrm{eff}}\right)$ in the sample was obtained using the Scherrer equation:

$$
D_{e f f}=\frac{0.9 \cdot \lambda}{\left(\gamma_{\text {exp }}-\gamma_{\text {instr }}\right) \cdot \cos (\theta)}
$$

Here $\lambda$ is the X-ray wavelength, 0.9 is an estimate of the Scherrer constant, $\gamma_{\exp }$ is the measured FWHM of the peak, and $\gamma_{\text {instr }}$ is the instrument broadening (as FWHM) of a pseudoVoight at the wavelength of the $\mathrm{ZnO}$ (100) diffraction peak. Strain effects were ignored. Instrument broadening was estimated from the line widths measured from $\mathrm{LaB}_{6}$ standard and was only $0.013^{\circ}$ at the relevant $2 \theta$.

X-ray diffraction experiments of powder samples were also performed using a laboratory Siemens D5000 Xray diffractometer with a graphite post monochromator with the following parameters: wavelength $1.5406 \AA$ $(\mathrm{Cu} \mathrm{K} \alpha)$, tube power $1.6 \mathrm{~kW}(40 \mathrm{kV}$ at $40 \mathrm{~mA})$, step size $=0.02^{\circ}$, time per step $=2 \mathrm{~s}$, divergent slit $=1^{\circ}$, 
receiving slit $=0.02 \mathrm{~mm}$, scan angle range $=3-80^{\circ}$. Scanning electron microscopy images were obtained using a Zeiss Supra 55VP SEM operating in high vacuum mode. An accelerating voltage of 5 to $20 \mathrm{kV}$ was used with 10 to $30 \mu \mathrm{m}$ aperture and images were obtained using an in-lens secondary detector. Thermogravimetric analysis (TGA) experiments were performed using TA Instruments-SDT 2960 with simultaneous DTA-TGA. A heating rate of $5{ }^{\circ} \mathrm{C} \cdot \mathrm{min}^{-1}$ was used in air atmosphere. BET specific surface area measurement was performed using Autosorb-1 from Quantachrome Instrument by the precise vacuum volumetric method for nitrogen chemisorption. Multi-point (5 points) measurement was conducted on the sample. For transmission electron microscopy (TEM) images, small amount of the powder samples was suspended in MilliQ water and sonicated. Then a drop of the dispersed solution was put in a carbon-coated copper grid and dried. The TEM images of samples were taken using a JEOL JEM-2200FS microscope at the accelerating voltage of $200 \mathrm{kV}$ equipped with EDS or JEOL 1400 microscope at the accelerating voltage of $120 \mathrm{kV}$.

Synthesis of zinc hydroxide carbonate

An aqueous solution of $\mathrm{ZnSO}_{4} \cdot 7 \mathrm{H}_{2} \mathrm{O}(30 \mathrm{ml}, 1 \mathrm{M}, \mathrm{pH}=6)$ and was added to the aqueous solution of $\mathrm{Na}_{2} \mathrm{CO}_{3}$ (30 $\mathrm{ml}, 1 \mathrm{M}, \mathrm{pH}=12)$ at $70{ }^{\circ} \mathrm{C}$ in a single step:

$5 \mathrm{ZnSO}_{4} \cdot 7 \mathrm{H}_{2} \mathrm{O}+5 \mathrm{Na}_{2} \mathrm{CO}_{3} \rightarrow \mathrm{Zn}_{5}\left(\mathrm{CO}_{3}\right)_{2}(\mathrm{OH})_{6(\mathrm{~s})}+5 \mathrm{Na}_{2} \mathrm{SO}_{4(\mathrm{aq})}+3 \mathrm{CO}_{2}+32 \mathrm{H}_{2} \mathrm{O}$

Immediately after the addition of zinc sulfate solution, the reaction started and the solution became white and cloudy. The reaction continued for 1 hour (where the $\mathrm{pH}$ of the system was 7) and then the suspension produced was kept still overnight to precipitate. Then the white precipitate was filtered, washed and dried.

Production of zinc oxide from zinc hydroxide carbonate

Zinc hydroxide carbonate was calcined to produce $\mathrm{ZnO}$. A bulk sample was prepared by placing into a preheated oven at $300{ }^{\circ} \mathrm{C}$ for one hour. Other samples of $\mathrm{ZnO}$ were prepared in the beam of the synchrotron by ramping the temperature at $5{ }^{\circ} \mathrm{C} \cdot \mathrm{min}^{-1}$ and examining in situ. If de-carboxylation and de-hydroxylation occurs simultaneously, then the reaction is

$$
\mathrm{Zn}_{5}\left(\mathrm{CO}_{3}\right)_{2}(\mathrm{OH})_{6} \rightarrow 5 \mathrm{ZnO}+3 \mathrm{H}_{2} \mathrm{O}+2 \mathrm{CO}_{2}
$$




\section{Results and Discussion}

A bulk sample of zinc hydroxide carbonate, $\mathrm{Zn}_{5}\left(\mathrm{CO}_{3}\right)_{2}(\mathrm{OH})_{6}$, was prepared according to Equation (2), a straightforward and well-known route that is also utilised industrially (Moezzi et al., 2012). The precipitate formed by this reaction was collected and characterised using powder XRD. The diffraction pattern corresponds reasonably to that of $\mathrm{Zn}_{5}\left(\mathrm{CO}_{3}\right)_{2}(\mathrm{OH})_{6}$, Fig. 1. Note, however, that the strong diffraction peak measured at $60^{\circ}$ is not well represented in the reference pattern (JC-PDF: 00-019-1458) used. It is likely that the slight mismatch between the measured and published patterns is due to small structural differences between our $\mathrm{Zn}_{5}\left(\mathrm{CO}_{3}\right)_{2}(\mathrm{OH})_{6}$ and that used to prepare the reference pattern.

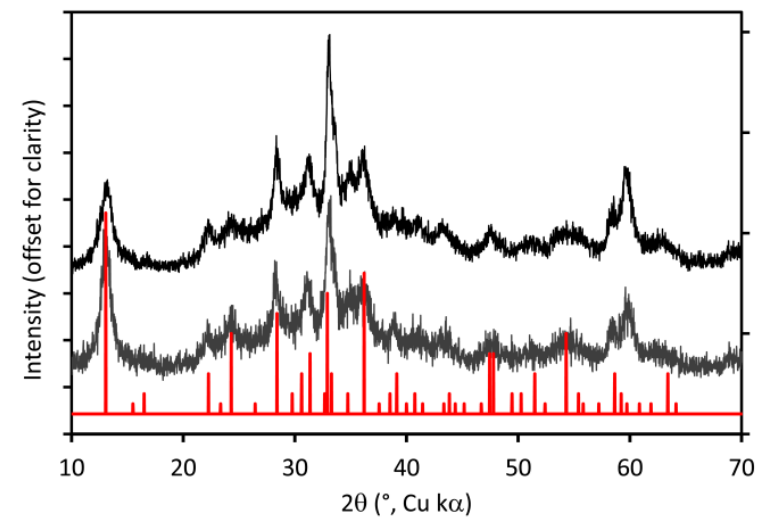

Fig. 1. Powder XRD patterns for two examples of the zinc hydroxide carbonate. Also shown are the lines for hydrozincite, JC-PDF: 00-019-1458.

The theoretical mass loss of $\mathrm{Zn}_{5}\left(\mathrm{CO}_{3}\right)_{2}(\mathrm{OH})_{6}$ when decomposed to $\mathrm{ZnO}$ is $\sim 25.9 \%$. TGA experiments revealed a mass loss of $\sim 26 \%$ up to a temperature of $1000{ }^{\circ} \mathrm{C}$, which is in accordance with the theoretical mass loss value. The sample contains a small amount of moisture. A small and gradual mass loss can be observed as the temperature is ramped up to $240{ }^{\circ} \mathrm{C}$. DTA shows a sharp endothermic peak starting at $\sim 230^{\circ}$ and reaching a maximum at $248^{\circ} \mathrm{C}$ along with a sharp mass loss seen in TGA, Fig. 2. The gradual further mass loss above 250 ${ }^{\circ} \mathrm{C}$ is attributed to the removal of surface hydroxyl groups (Moezzi et al., 2011). 


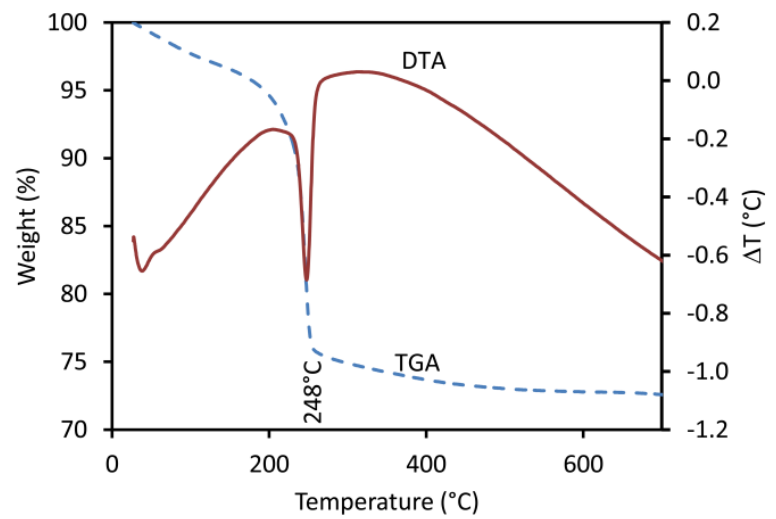

Fig. 2. TGA-DTA on hydrozincite sample showing endothermic decomposition to $\mathrm{ZnO}$ at $248^{\circ} \mathrm{C}$.

A portion of $\mathrm{Zn}_{5}\left(\mathrm{CO}_{3}\right)_{2}(\mathrm{OH})_{6}$ was calcined at $300{ }^{\circ} \mathrm{C}$ for 1 hour. It was observed that the product at $300{ }^{\circ} \mathrm{C}$ shows a yellowish-white colour, but the sample regained its whiteness once cooled to room temperature. This is in accordance with the thermochromic property of $\mathrm{ZnO}$ (Auer et al., 2005). XRD on the calcined product showed that the product is $\mathrm{ZnO}$, Fig. 3. SEM images of the $\mathrm{Zn}_{5}\left(\mathrm{CO}_{3}\right)_{2}(\mathrm{OH})_{6}$ and the highly porous $\mathrm{ZnO}$ produced from this precursor are shown in Fig. 4. It appears that the $\mathrm{ZnO}$ product is pseudomorphous with the hydrozincite precursor, as previously reported (Castellano and Matijevic, 1989, Kanari et al., 2004). However TEM images, Fig. 5, revealed that the $\mathrm{ZnO}$ pseudomorphous product is actually a polycrystalline aggregate comprised of individual crystals with sizes in the range of 5 to $20 \mathrm{~nm}$. Amorphous material was also detected. Both of these observations are consistent with the XRD pattern of this sample, which shows only relatively low intensity peaks for $\mathrm{ZnO}$.

Comparison of zinc oxide made from this route with products made from zinc hydroxide sulfate (Moezzi et al., 2013a) and zinc hydroxide acetate (Moezzi et al., 2013b) shows that there are significant differences between the crystal sizes and morphologies. In particular, the present material is highly porous and non-uniform in shape, whereas materials made from calcination of zinc hydroxide acetate or zinc hydroxide sulfate are moreuniform in shape and more crystalline. 


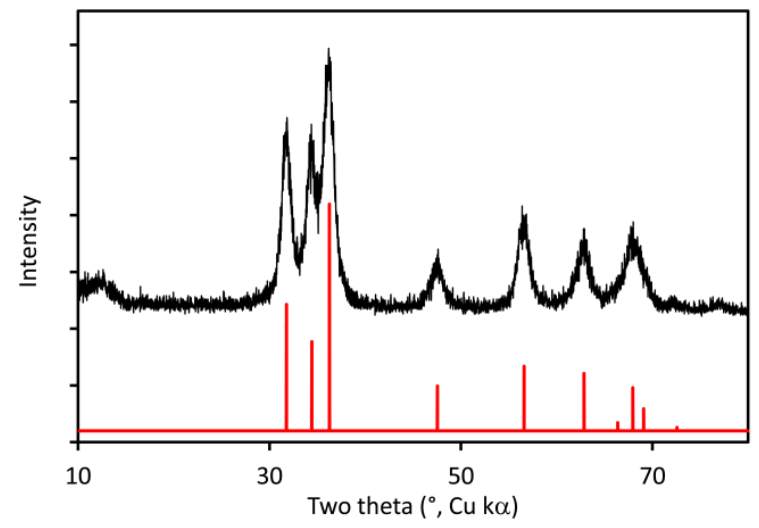

Fig. 3. XRD $(\mathrm{Cu} \mathrm{K} \alpha)$ on the calcined product corresponds to ZnO (JC-PDF: 00-005-0664).
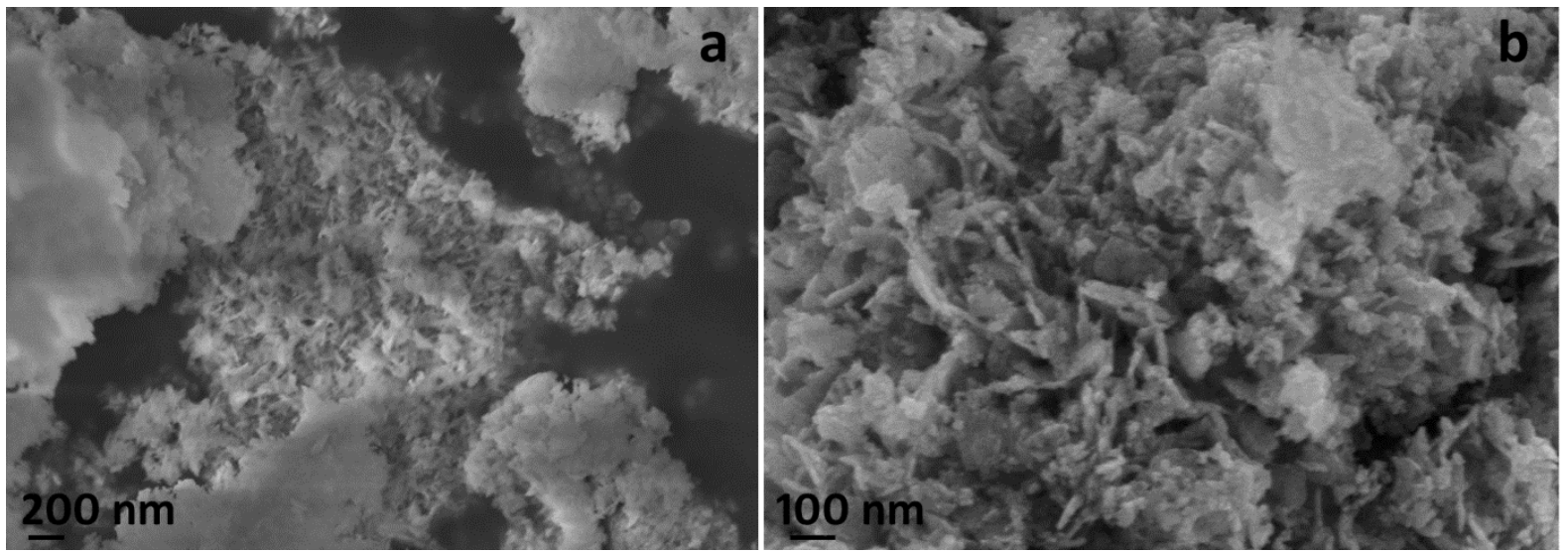

Fig. 4. SEM images of (A) $\mathrm{Zn}_{5}\left(\mathrm{CO}_{3}\right)_{2}(\mathrm{OH})_{6}$ and (B) highly porous $\mathrm{ZnO}$ produced by calcination of $\mathrm{Zn}_{5}\left(\mathrm{CO}_{3}\right)_{2}(\mathrm{OH})_{6}$.

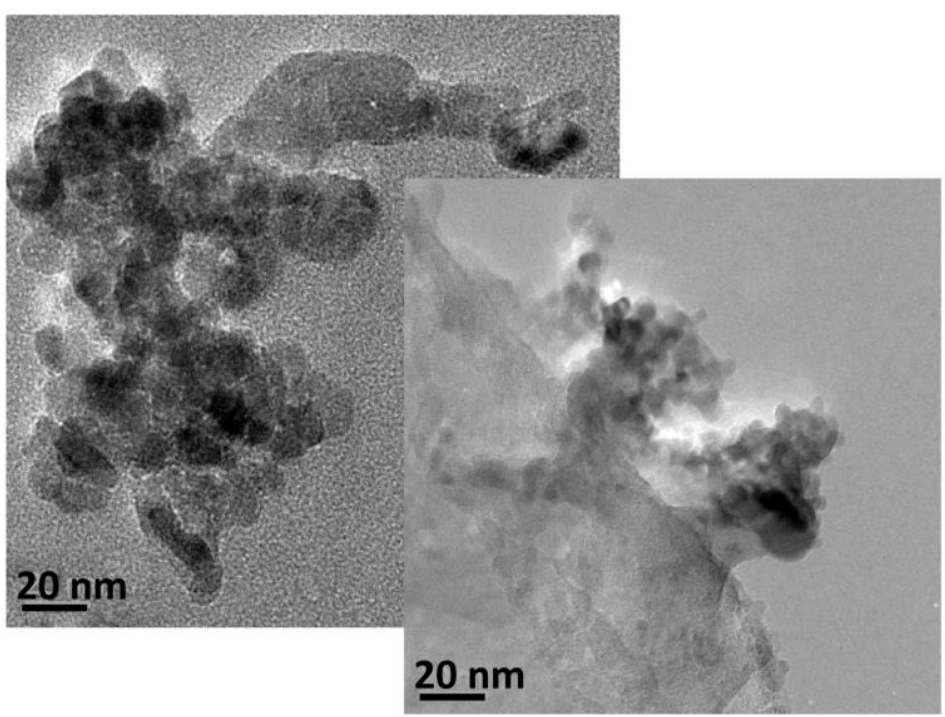

Fig. 5. TEM images of the $\mathrm{ZnO}$ particles produced from calcination of $\mathrm{Zn}_{5}\left(\mathrm{CO}_{3}\right)_{2}(\mathrm{OH})_{6}$ at $300{ }^{\circ} \mathrm{C}$. Individual crystalline cores are surrounded by an amorphous shell. 
An in-situ synchrotron XRD study of $\mathrm{Zn}_{5}\left(\mathrm{CO}_{3}\right)_{2}(\mathrm{OH})_{6}$ between $25^{\circ} \mathrm{C}$ to $600{ }^{\circ} \mathrm{C}$ confirmed that a single-stage phase transformation occurs to form $\mathrm{ZnO}$, Fig. 6, at least to within the resolution of the techniques used. Up to temperatures of $\sim 235{ }^{\circ} \mathrm{C}$, only $\mathrm{Zn}_{5}\left(\mathrm{CO}_{3}\right)_{2}(\mathrm{OH})_{6}$ peaks were detected, with shrinkage in peak intensity as temperature increases. A phase transformation occurred at $\sim 235^{\circ} \mathrm{C}$ and only $\mathrm{ZnO}$ peaks are evident beyond this temperature. This is in contrast to the decomposition of other basic zinc salts such as zinc hydroxide acetate or zinc hydroxide sulfate, which pass through a series of intermediate phases en route to becoming $\mathrm{ZnO}$ (Moezzi et al., 2013a, Moezzi et al., 2013c). The estimated size of the $\mathrm{ZnO}$ crystallites is shown in Fig. 7.

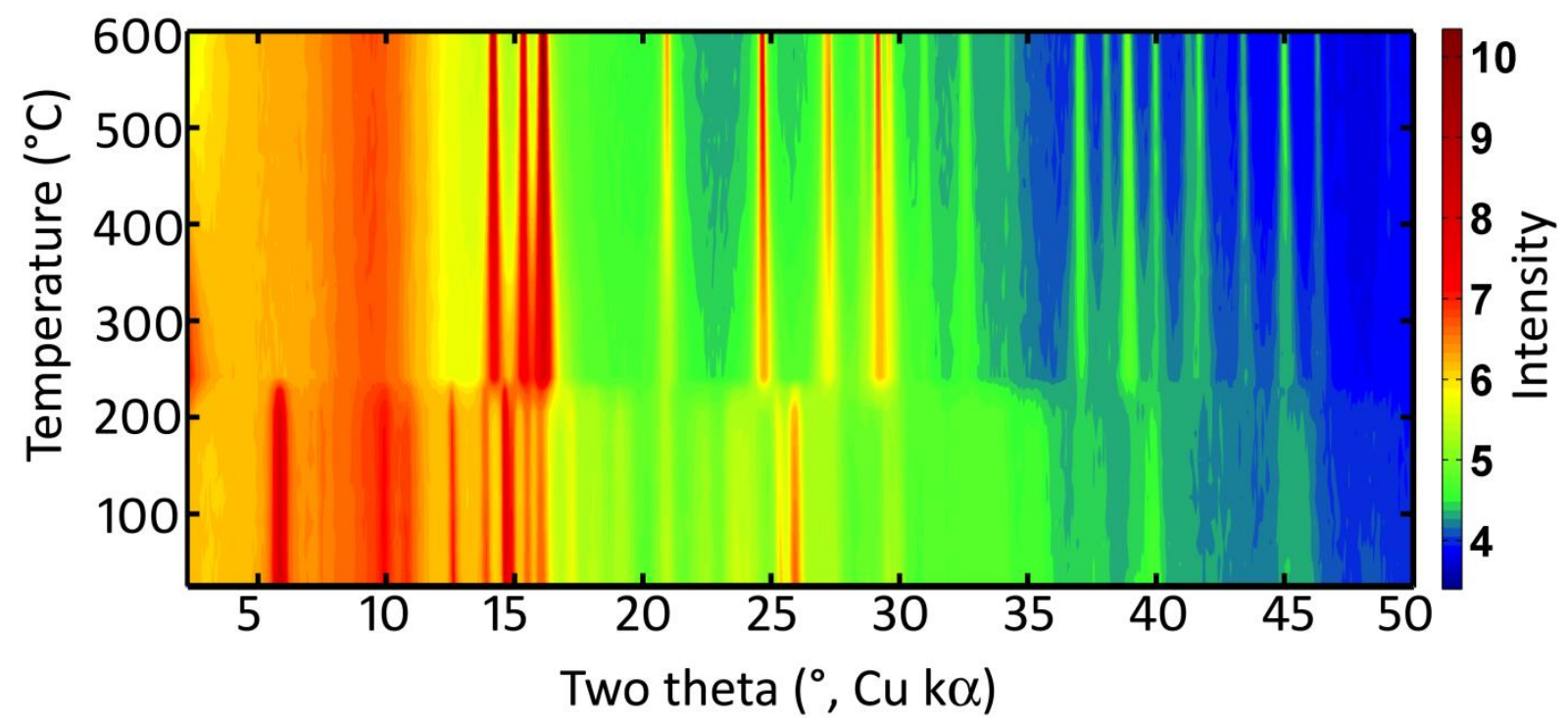

Fig. 6. Colour-coded contour graph showing powder XRD data collected from hydrozincite sample during in-situ experiment between $25^{\circ} \mathrm{C}$ to $600{ }^{\circ} \mathrm{C}$.

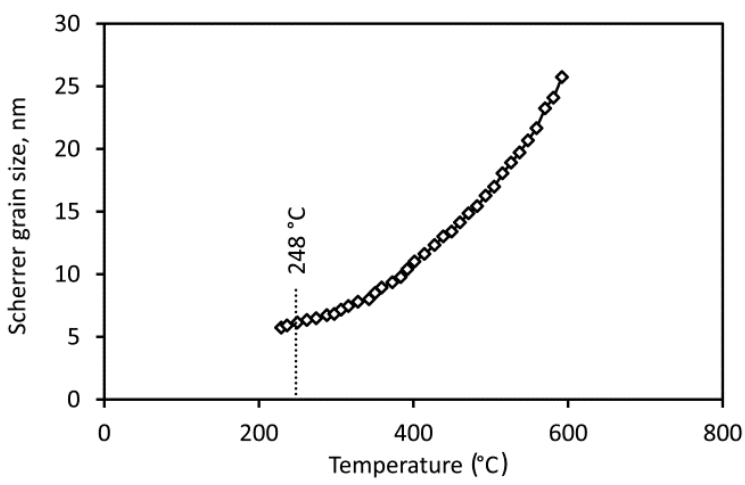

Fig. 7. Estimate of the $\mathrm{ZnO}$ crystallite size obtained from the Scherrer equation, as applied to the (100) line of $\mathrm{ZnO}$, as a function of the temperature during a calcination ramp at $5{ }^{\circ} \mathrm{C} \cdot \mathrm{min}^{-1}$. 
It was interesting to observe, however, that the scattering signal at the lowest values of $2 \theta\left(2.2^{\circ}\right.$ here $)$ peaked immediately after the phase transformation, Fig. 8. This signal is generated by scattering between crystalline domains rather than from within them. Its presence is an indication that the crystalline $\mathrm{ZnO}$ domains at that temperature are spatially separated from one another by either gaseous or amorphous zones. However, inspection of the integrated area under the $\mathrm{ZnO}$ peak showed only the usual monotonic decline with temperature, strongly suggesting that the intervening volume was gaseous. (If the intervening spaces had been filled with an initially amorphous solid then an increase in the $\mathrm{ZnO}$ volume fraction would have been expected as calcination progressed due to that solid converting to crystalline $\mathrm{ZnO}$.) In any event, as the temperature is raised further, the scattering diminishes to its baseline level, indicating that the intervening spaces or material between the $\mathrm{ZnO}$ crystallites have disappeared, i.e. the particles of $\mathrm{ZnO}$ have become consolidated.

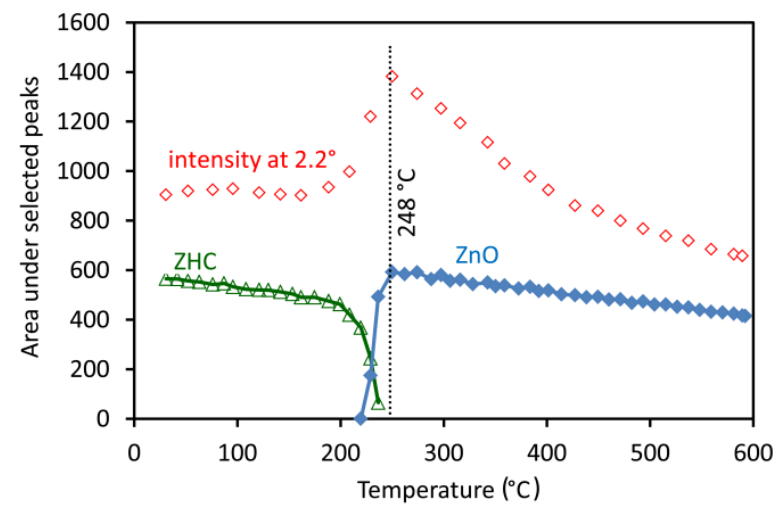

Fig. 8. X-ray scattering at low angles $\left(2.2^{\circ}\right)$ reaches a peak just after the decomposition of zinc hydroxide carbonate is complete. This peak indicates a transient, porous morphology. Also shown are the integrated areas under a selected peak apiece for the zinc hydroxide carbonate and the $\mathrm{ZnO}$.

To investigate the effect of temperature of calcination on the specific surface area of $\mathrm{ZnO}$ product, some $\mathrm{Zn}_{5}\left(\mathrm{CO}_{3}\right)_{2}(\mathrm{OH})_{6}$ was divided into 11 parts and the samples were calcined at a temperature range of $250-350{ }^{\circ} \mathrm{C}$ (with $10{ }^{\circ} \mathrm{C}$ intervals) for 1 hour, respectively. After calcination, all products were characterized by a laboratory XRD to be ZnO, Fig. 9. Although the FWHM of the $\mathrm{ZnO}$ (100) line was dominated by instrument broadening, a decrease from about $1.10^{\circ}$ to about $0.95^{\circ}$ as the temperature of calcination was increased could be detected. It was expected that BET specific surface area would decline with increase of the temperature of calcination from 250 to $350{ }^{\circ} \mathrm{C}$ but the BET specific surface area of these samples was measured to be in the range of $47-65 \mathrm{~m}^{2} / \mathrm{g}$, without any statistically valid trend, Fig. . These sizes notionally correspond to a particle diameter in the range of 15 to $22 \mathrm{~nm}$. Nevertheless, these surface areas are still much higher than those of materials prepared by the French and American processes (Moezzi et al., 2012), the direct precipitation method (Moezzi et al., 2011), or from thermal decomposition of zinc hydroxide acetate (Moezzi et al., 2013b) or zinc hydroxide sulfate (Moezzi et al., 2013a).

It is interesting to note that however that the implication of the in situ synchrotron measurements is that, if the sample could be quenched immediately after the decomposition had taken place, then a specific surface area of the order of $180 \mathrm{~m}^{2} / \mathrm{g}$ should in theory be attainable based on the crystallite size estimated using the Scherrer approach. This will be investigated in future work. 


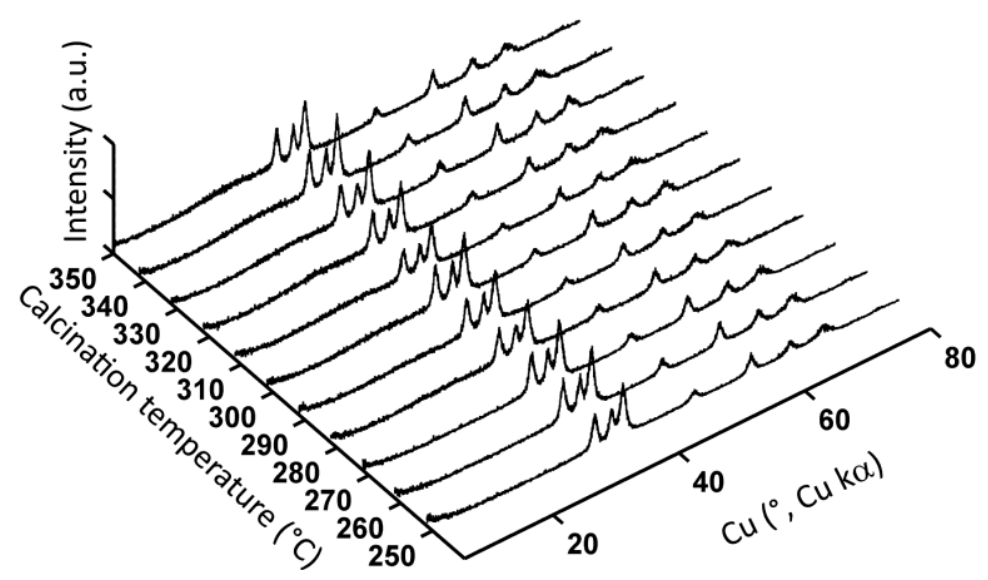

Fig. 9. $\mathrm{XRD}(\mathrm{Cu} \mathrm{K \alpha})$ on the products of calcination of $\mathrm{Zn}_{5}\left(\mathrm{CO}_{3}\right)_{2}(\mathrm{OH})_{6}$ between $250-350{ }^{\circ} \mathrm{C}$ for 1 hour shows only $\mathrm{ZnO}$ peaks.

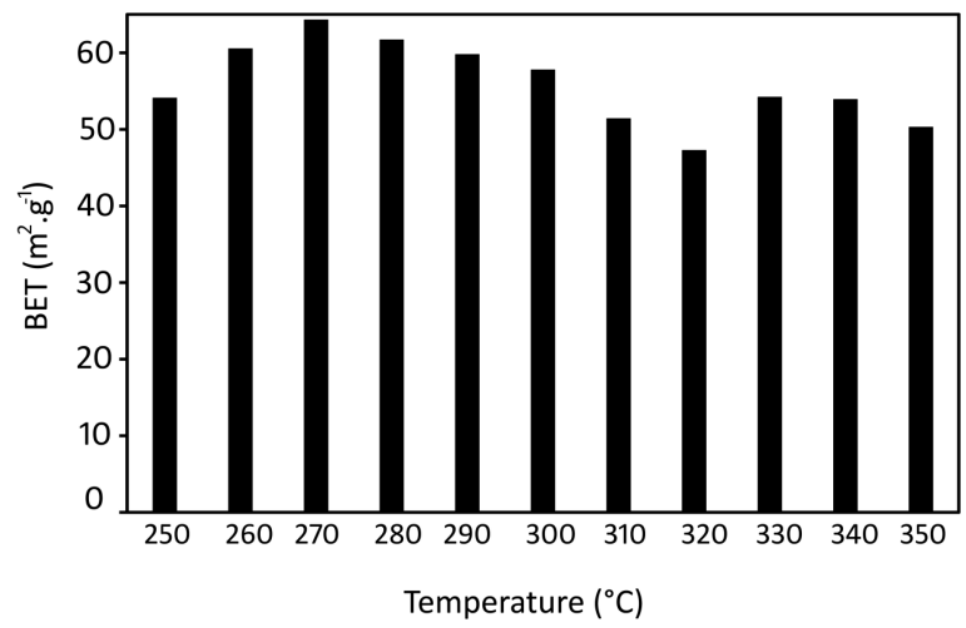

Fig. 10. BET specific surface area of $\mathrm{ZnO}$ samples prepared by calcination of $\mathrm{Zn}_{5}\left(\mathrm{CO}_{3}\right)_{2}(\mathrm{OH})_{6}$ at $250-350$ ${ }^{\circ} \mathrm{C}$.

\section{Conclusions}

Zinc hydroxide carbonate $\left(\mathrm{Zn}_{5}\left(\mathrm{CO}_{3}\right)_{2}(\mathrm{OH})_{6}\right)$ can be produced by a reaction between aqueous solutions of zinc sulfate and sodium carbonate with 1:1 molar ratio. This substance can then be used as the precursor for production of so-called 'active zinc oxide' with a high specific surface area. At a heating rate of about 5 ${ }^{\circ} \mathrm{C} \cdot \mathrm{min}^{-1}$, the decomposition to form $\mathrm{ZnO}$ occurs in a single step at around $240{ }^{\circ} \mathrm{C}$. The specific surface area of the $\mathrm{ZnO}$ synthesized by this route is higher than those of $\mathrm{ZnO}$ made by the French and American processes direct precipitation, or thermal decomposition of zinc hydroxide acetate and zinc hydroxide sulfate. Crystal size 
of the $\mathrm{ZnO}$ particles (observed by TEM) is between 5 to $20 \mathrm{~nm}$ with some amorphous material detected in the mixture. In situ XRD analysis in a synchtrotron revealed that the particles coarsen quite rapidly after their initial nucleation. We propose that ultrafine $\mathrm{ZnO}$ particles could be obtained by quenching the material immediately after decomposition has taken place so that coarsening is avoided.

\section{Acknowledgment}

This work was supported by PT. Indo Lysaght (Indonesia). The in-situ XRD was undertaken on the Powder Diffraction beamline at the Australian Synchrotron, Victoria, Australia.

\section{References}

Auer G, Griebler W-D, Jahn B (2005) Industrial Inorganic Pigments, Weinheim, Wiley-VCH Verlag GmbH \& Co. KGaA.

Castellano M, Matijevic E (1989) Uniform colloidal zinc compounds of various morphologies. Chemistry of Materials 1:78-82.

Dollimore D, J.A. France, Krupay BW, Whitehead R (1980) Kinetic aspects of the thermal decomposition of zinc carbonate. Thermochimica Acta 36:343-349.

Kanari N, Mishra D, Gaballah I, Dupré B (2004) Thermal decomposition of zinc carbonate hydroxide. Thermochimica Acta 410:93-100.

Li Z, Shen X, Feng X, Wang P, Wu Z (2005) Non-isothermal kinetics studies on the thermal decomposition of zinc hydroxide carbonate. Thermochimica Acta 438:102-106.

Liandi S (1995) World development of active zinc oxide. Modern Chemical Industry 7:12-14 (in Chinese).

Liu Y, Zhao J, Zhang H, Zhu Y, Wang Z (2004) Thermal decomposition of basic zinc carbonate in nitrogen atmosphere. Thermochimica Acta 414:121-123.

Moezzi A, Cortie M, McDonagh A (2011) Aqueous pathways for the formation of zinc oxide nanoparticles. Dalton Transactions 40:4871-4878.

Moezzi A, Cortie MB, McDonagh AM (2013a) Zinc hydroxide sulphate and its transformation to crystalline zinc oxide. Dalton Trans. 42:4432 - 14437.

Moezzi A, McDonagh A, Dowd A, Cortie M (2013b) Zinc Hydroxyacetate and Its Transformation to Nanocrystalline Zinc Oxide. Inorganic Chemistry 52:95-102.

Moezzi A, McDonagh AM, Cortie MB (2012) Zinc oxide particles: Synthesis, properties and applications. Chemical Engineering Journal 185-186:1-22.

Moezzi A, McDonagh AM, Dowd A, Cortie MB (2013c) Zinc hydroxy acetate and its transformation to nanocrystalline $\mathrm{ZnO}$. Inorganic Chemistry 52:95-102.

Nip RL (2003) Method of preparing zinc ammonia carbonate solution. United States Patent 20030152508.

Nobari AH, Halali M (2006) An investigation on the calcination kinetics of zinc carbonate hydroxide and Calsimin zinc carbonate concentrate. Chemical Engineering Journal 121:79-84.

Robinson VS (1978) Method for preparing particulate zinc oxide shapes of high surface area and improved strength. United States Patent 4,071,609.

Sawada Y, Murakami M, Nishide T (1996) Thermal analysis of basic zinc carbonate. Part 1. Carbonation process of zinc oxide powders at 8 and $13^{\circ} \mathrm{C}$. Thermochimica Acta 273:95-102.

Wojdyr M (2010) Fityk : a general-purpose peak fitting program. J. Appl. Cryst. 43:1126-1128. 